Rev Soc Esp Dolor

2015; 22(2): 87-88

\section{El trabajo multidisciplinar en el abordaje del dolor crónico. La hipnosis como coadyuvante}

\section{Sr. Director:}

El dolor crónico es aquel que dura más de 6 meses sufriéndose por 1 de cada 6 españoles (1). Es el síntoma que con más frecuencia motiva una consulta médica, generalmente de atención primaria $(1,2)$. En este puede existir una causa conocida (como por ejemplo, hernia, traumatismos, fracturas, artritis, fibromialgia, tumores, postoperatorios, patologías y disfunciones varias) y/o desconocida, donde el estrés parece estar en el origen del dolor. Con todo ello, es uno de los trastornos que más afecta y preocupa a las personas por sus importantes repercusiones negativas en su vida emocional, social, laboral y familiar con la consiguiente merma en la calidad de vida de las mismas y en muchos casos con síntomas asociados de ansiedad y depresión, entre otros $(1,2)$.

Por tanto, el dolor crónico es un fenómeno complejo y multifactorial que depende de factores fisiológicos, psicológicos y socioculturales, de ahí que el abordaje del dolor crónico tenga que ser multidisciplinar desde una perspectiva biopsicosocial donde se integren distintas especialidades. Sólo los programas integrales han mostrado una elevada eficacia y costo-efectividad en la calidad de vida del paciente con dolor crónico (2). Desde este enfoque multidisciplinar, y dado el efecto psicológico que tiene el dolor crónico sobre la calidad de vida del enfermo y de sus familiares (3), hay que añadir al tratamiento farmacológico y al resto de tratamientos médicos, el psicológico.

Existe evidencia científica sobre la efectividad y eficacia de distintos tratamientos psicológicos en la mejora de la calidad de vida del paciente que sufre dolor crónico $(4,5)$. Uno de ellos hace referencia a la hipnosis. Afortunadamente en los últimos años, el uso de la hipnosis como técnica de intervención en el área de la salud ha demostrado su eficacia no sólo como tratamiento de utilidad en pacientes con dolor crónico, disminuyéndose la intensidad del dolor y la cantidad de fármacos a consumir, sino que ha demostrado altas tasas de éxito en otros tipos de patologías e intervenciones $(2,4,6)$.

La hipnosis es una técnica de focalización selectiva de la atención en la que el paciente en un estado de relajación profunda está más permeable y receptivo a una serie de sugestiones. Las más habituales son la analgesia (ausencia de la sensación de dolor), anestesia (ausencia de cualquier tipo de sensación), sustitución del dolor (por un hormigueo, un picor, por ejemplo), desplazamiento del dolor (de un área a otra del cuerpo), disociación hipnótica (el paciente es inducido a experimentarse a sí mismo como fuera de su cuerpo u orientado a una época pasada o futura de su vida sin dolor), reinterpretación de la experiencia del dolor (el dolor lacerante, por ejemplo, es interpretado como un sobresalto repentino y momentáneo), la distorsión hipnótica del tiempo (aumentar la percepción subjetiva del tiempo que el paciente permanece en un periodo indoloro y disminuir la percepción temporal de los accesos de dolor) y la disminución progresiva del dolor (5).

El profesional adecuado para aplicar esta técnica psicológica es el licenciado en psicología cuya formación en hipnosis haya tenido lugar en centros especializados y acreditados para ello. Por tanto, es necesaria y prioritaria la presencia de dicho profesional, con formación en hipnosis, en la sanidad pública y privada, sobre todo en las unidades de tratamiento del dolor (UTD), así como en los servicios de reumatología y traumatología. Sin embargo, los datos son bastantes desalentadores, ya que sólo en el $37 \%$ de las UTD de los hospitales españoles existe un especialista en psicología con dedicación parcial (2).

Además, aún deben superarse algunos obstáculos como son la escasa presencia de la hipnosis en la investigación y en la formación universitaria, debido a que por desconocimiento ha sido asociada a poca validez científica, junto a una cantidad de mitos y de creencias erróneas hacia la hipnosis que debemos comenzar a desmitificar desde los foros académicos y científicos para colocarla en el lugar que le corresponde $(4,6)$.

Por tanto, es prioritario integrar dentro de nuestra sanidad a los profesionales de la psicología con formación en hipnosis o en su caso a médicos, enfermeras o fisioterapeutas que cuenten con una amplia formación en dicha materia en universidades, colegios profesionales y centros especializados $(4,6)$ para dar el mejor tratamiento a los pacientes que ven mermada su calidad de vida por el dolor crónico, apostando por una verdadera integración multidisciplinar donde la hipnosis sea un coadyuvante al resto de tratamientos farmacológicos y médicos.

\section{Martínez-Lorca', M.C. Zabala-Baños ${ }^{2}$} y R. Aguado Romo ${ }^{3}$

${ }^{1}$ Departamento de Psicología. Universidad de Castilla-La Mancha. ${ }^{2}$ Departamento de Enfermería, Fisioterapia y Terapia Ocupacional. Universidad de Castilla-La Mancha. ${ }^{3}$ Instituto Europeo de Psicoterapias de Tiempo Limitado 


\section{BIBLIOGRAFÍA}

1. Torralba A, Miquel M, Darda J. Situación actual del dolor crónico en España: iniciativa "Pain proposal". Rev Soc Esp del Dolor 2014;21(1):16-22.

2. Unidad de tratamiento del dolor. Estándares y recomendaciones de calidad y seguridad. Informes, estudios e investigación. Ministerio de Sanidad, Política Social e Igualdad; 2011.
3. Failde I. El dolor crónico, algo más que un problema de quien lo padece. Rev Soc Esp del Dolor 2014;21(1):1-2.

4. Martínez-Pintor F, Durany-Pich N. El dolor de espalda bajo una visión psicosomática. Hipnológica 2010;3:8-13.

5. Pérez JA, Fernández JC, Fernández B, Durán M. Empleo de metáforas en las sugestiones hipnóticas para manejar el dolor articular: estudio de caso. Revista de Psicopatología y Psicología Clínica 2012;17(1):57-73.

6. Benito LM, Aguado R. More on sedation in digestive endoscopy. Rev Esp Enferm Dig 2009;101(7):483-91. 